\title{
Chemical alteration of banana pseudostems by white rot fungi
}

\begin{abstract}
The ability of fungi to degrade lignocellulosic materials is due to their highly efficient enzymatic system. However, many of these fungi have the ability to not only depolymerize and metabolize lignin but also to degrade cellulose and hemicellulose. This study aims to investigate the differences between white rot fungi species, namely, Pycnoporus sanguineus, Oxyporus latemarginatus, Coriolus versicolor, and Rigidoporus vinctus, in chemical constituent changes on the pseudostem of Musa acuminata var. truncata. The sterilized banana pseudostem chips were inoculated with each fungus separately and incubated for 1, 2 and 4 weeks. P. sanguineus was found to be the best fungus for banana pseudostem among 4 species because it degraded mainly on lignin and extractives but less on holocellulose and alpha-cellulose. On the other hand, O. latemarginatus was found to degrade all the chemical contents, while $\mathrm{C}$. versicolor and $\mathrm{R}$. vinctus appeared less efficient in banana degradation. It appeared that the suitable pre-treatment duration was two weeks, which was due to the lower amounts of degraded holocellulose and alpha-cellulose.
\end{abstract}

Keyword: Pycnoporus sanguineus; Pre-treatment; Musa accuminata var. trunscata; Chemical alteration; Oxyporus latemarginatus; Coriolus versicolor 